\title{
Determination of Antioxidants and Antimicrobial Activities of Platytaenia multicaule
}

\author{
Najeebullah Kakar ${ }^{1,2}$, Samiullah ${ }^{1}$, Naqeebullah Khan ${ }^{1}$, Attiq-ur-Rehman Kakar ${ }^{1 *}$, Rasool Bakhsh \\ Tareen $^{3}$, Nazia Meer ${ }^{1}$, Syed Waheed Ahmed Shah ${ }^{1}$, Irshad Ali ${ }^{1}$, Muhammad Asghar ${ }^{1}$ and \\ Abdul Baqi Achakzai ${ }^{1,2}$ \\ ${ }^{1}$ Department of Chemistry, University of Balochistan, Quetta 87300-Pakistan \\ ${ }^{2}$ Department of Botany, University of Balochistan, Quetta 87300-Pakistan \\ ${ }^{3}$ Colleges, Higher and Technical Education Department, Balochistan, Quetta 87300-Pakistan \\ *Corresponding author: arkakarlo@gmail.com
}

\begin{abstract}
Determination of antioxidants and antibacterial activities of an important medicinal plant like Platytaenia multicaule has been accomplished for the first time in this contest. Regarding antioxidants and antibacterial activities, the plant was analyzed chemically by means of four well known methods as well as by UV/VIS spectroscopic techniques. The crude extract was obtained from the plant by the utilization of methanol $(\mathrm{MeOH})$ and the antioxidants activities of the crude extract tested. Furthermore, using spectrophotometer the antioxidants capacities were examined via 2,2-Diphenyl-1-Picrylhydrazyl (DPPH) Assay, Total Antioxidant Capacity (TAC), Ferric Reducing Antioxidant Power (FRAP) Assay and Reducing Power (RP) Assays. The capacity of DPPH Assay of $P$. multicaule was $190 \mathrm{mg} / \mathrm{g}$ of ascorbic acid concentration. Additionally, for the TAC and FRAP the values of extracts were $10.85 \mathrm{mg}$ and $40 \mathrm{mg}$ of ascorbic acid/g of $P$. multicaule extract respectively. In addition, the RP shows $3.29 \mathrm{mg} / \mathrm{g}$ of ascorbic acid concentration. The $P$. multicaule have shown the high antioxidant activity. On the other hand, the antibacterial activity of this plant was investigated by the agar well diffusion method. In this, the plant extracts were examined against two bacteria namely Escherichia coli and Staphylococcus aureus which exhibited $14 \mathrm{~mm}$ and $16 \mathrm{~mm}$ zones of inhibition respectively. Hence, this test proved that the P. multicaule contains high antibacterial agents. [DOI: 10.22401/ANJS.22.4.04]
\end{abstract}

Keywords: Antioxidant activity, DPPH, TAC, FRAP, RP, Antibacterial activity, Agar.

\section{Introduction}

In past era, plants have been used as medicines i.e. spices and culinary herbs, not effective necessarily. In warm weather, for food wastage spices have been used. Mostly for meat decay [1]. Flowering plants were the basic source of medicine. In which check weed and netle were used as medicine [2]. The important role of therapeutic plants is to support all the time in the synthesis of numerous useful medicines. It gives various drugs of identified medicinal results. Innate awareness concerning plants drug is an unlimited source of modern information. Drugs are mainly obtained from medicinal plants which inhibit the growth of microorganisms as well as their harmful activities. The tribal people are well aware about their antibiotic activities; hence they use them for the treatment of various disorders. Now-a-days numerous plants are usually treated as medicine. They are examined for having biological accomplishments and biochemical constituents [3]. Lavender plant having purple flower belong to family lamiaceae. It is distributed in Europe, America and Asia. The plant extract is used for chemotherapy, pharmaceutical, insect bites, skin disorders and other gastrointestinal illnesses [4].

The vegetation of Pakistan is filled with medicinal plants because of its soil condition, ecological areas and diverse climate change. A survey has realized that in Pakistan, 6000 species of flowering plants are existing in which almost 400-600 are homeopathically significant species $[5,6]$. Many plants have tendency in the treatment of disorders and can be used as natural guardian. In Pakistan, the District Ziarat of Balochistan province has adequate medicinal plants. These are advantageous and can be exercised as natural therapy counter to sicknesses [7]. 
The information about antioxidant capability of phytochemical ingredients present in particular plants is correspondingly vital due to the homoeopathic characteristics [8]. Antioxidants are molecules that stop the oxidation of other molecule which in their absence result in the generation of free radicals causing the destruction of human cells and tissues. Modern studies have proved to use sufficient amount of antioxidants reduces the menace of malignancy and many other related oxidative-stress sicknesses $[9,10]$. Antioxidants serve as diet additive to assist the protection of two key aspects in oxidation needed for body. Nutrition supplied in antioxidants can show activity against illnesses [11]. Fresh fruits and vegetables packing hold approximately $8 \%$ oxygen. Antioxidants are particularly significant group of additives as, contrasting from microbial, where oxidation reactions take place moderately fast in frozen foods [12]. These additives hold usual antioxidants i.e. ascorbic acid also known as vitamin $\mathrm{C}$ and artificial antioxidants such as propyl gallate, tertiary butylhydroquinone and butylated hydroxytoluene [13, 14]. Oxidation most commonly affects the unsaturated fats and similar other molecules as well [15].

The antioxidants found in plants are known to be very active as compare to those which are present in fruits and tubers [16]. Hence, plant extracts are examined for the antioxidant power and as well as to separate antioxidants that are very reactive and less harmful for organisms [17]. As a result, it is of great significant to the people, to know the antioxidant power of different eatable and medicinal plants.

The new compound known as coumarins existing in the form of pyrone ring, isolated from Tonka bean of plant kingdom. It has more pharmacological applications against Alzheimer and tuberculosis and as well as employed as antitumor and antimicrobial [18].

Biological activity shows the good or bad effect of drugs on organisms [19]. This activity is due to the active component of a substance. Different properties of a compound, for example, bioactivity plays a vital role. A substance is considered to be biologically active when it interacts with cells and tissues of body. Molecular properties comprise on physical, chemical and structural properties. Including drugs, molecular properties of substances do not contain biological properties [20]. Across the world, 85000 medicinal plants are reported. Drugs are primarily developed via isolation of bioactive compounds from plants which are determined through medical uses [21]. Many experts worked on medicinal plants, only few of them determined their biological activities. In developing countries, drugs are not available to all. For this reason, $80 \%$ people of the world use plants for the treatment of diseases [22]. Those countries where drugs are not available, they need to determine the bioactivities of medicinal plants [23]. Many researchers mentioned extract and bioactive components of plants as a promising drug [24]. Recently, certain chemical compounds have been synthesized to overcome the issue of bacterial infections. One of the significant compound is thiadiazoles which is hetero atomic aromatic compound. It can exist in four isomeric form and the most stable isomer among all is 1,3,4-thiadiazole. Its stability is increased by the substituents attached on $\mathrm{C} 2$ and $\mathrm{C} 5$. It has various forms because of the capability to undergo through the tautomerism process. 1,3,4-thiadiazol shows antifungal and antibacterial activities [25].

Fig.(1) shows the picture of the plant Platytaenia multicaule (E. Nasir), locally known as Kumala. It is an important member of Umbelliferae family. This family comprises of approximately three thousand species, 56 genera and about 167 species have been identified in Pakistan. The plants of this family have the following characteristics: annual, biennial, perennial and erect decumbent or prostrate, mostly herbaceous glabrous, pubescent or spiky. Having alternative branching or dichotomous, roots are tap or alternate, frequently hollow stem and leaves are simple or complex. The Umbelliferae is diverse famous family and possessing greater development in the moderate zone. A few of them are xerophyte and most of them are mesophyte.

The Genus Platytaenia is the main part of family Umbelliferae. This genus comprises of about 10 species which is distributed from central Asia to Iran, Afghanistan and Pakistan, 
including Platytaenia multicaule which is found in village Spazandi of District Ziarat.

It is distributed in Balochistan province especially in District Ziarat at various locations such as village Spazandi, Sarbara Tangi and Kharvari Baba. This taxon is collected from the aforementioned localities only. It varies from p-lasiocarpa in the figure texture and pubescence of leafless, limited rays and thin fruits at the base.

It is very famous in the indigenous community of District Ziarat. Many people put the name of their daughter on native name of this plant (KUMALA). The people dry the whole plant instead of its root, make powder of it and in the winter season, they utilize the powder as a preservative for the meat of sheep locally known as landi. Its powder has been used for the healing of wounds and has also been used as a condiment and carminative.
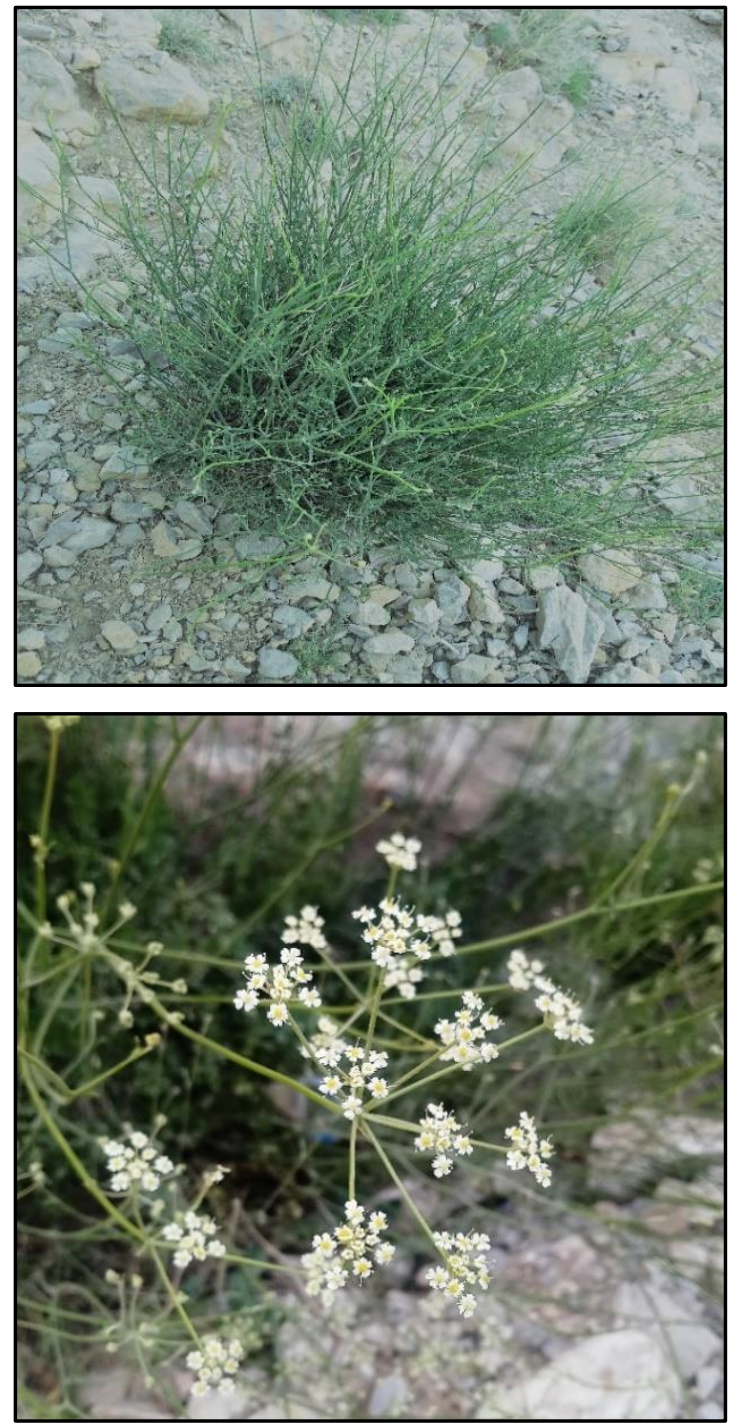

Fig.(1): Pictures of Platytaenia multicaule collected from District Ziarat.
In this work, the antioxidant and antibacterial activities of methanolic extract of medicinally important plant: Platytaenia multicaule have been determined employing DPPH assay, TAC, FRAP assay and RP assays. In addition, the antibacterial activity of the plant extract was investigated by the agar well diffusion method against two bacteria namely Escherichia coli and Staphylococcus aureus.

\section{Experimental \\ Materials and Methods}

The apparatus utilized during the research work are given as: all the chemicals and reagents used were of analytical grade. Potassium ferricyanide, methyl alcohol, trichloroacetic acid (TCA reagent), ferric chloride, sodium carbonate, aluminumtrichloride, sodium nitrate and sodium hydroxide were obtained from Merck (Darmstadt, Germany). Ascorbic acid, gallic acid and 2,2-diphenyl-1-picrylhydrazyl $(\mathrm{DPPH})$ were acquired from Sigma Aldrich (Buchs, Switzerland). A vacuum rotary evaporator utilized to remove methyl alcohol from the plant extract (vacuum rotary evaporator, KARL KOLB, Germany). Magnetic stirrer (JENWAY-1000 Hot plate Magnetic stirrer) used for stirring during extraction and homogenization, a centrifuge (EBA 20, Hettich Zentrifugen) was used for the phase separation. A double beam UV/Vis spectrophotometer (Shimadzu, Model UV1700, Japan) was used for the measurement of absorbance in the research work.

\section{Plant collection and Storage}

The medicinal plant was assembled from the mountains of Spazandi village situated in District Ziarat. Then the specimen was recognized by Prof. Doctor RB Tareen at Botany Department, University of Balochistant Quetta.

\section{Extraction and Purification}

The whole plant materials were dried out under shadow in the absence of light. They were cut and grinded into the powdered form weighing $3 \mathrm{~kg}$, out of which $1 \mathrm{~kg}$ was immersed in $7 \mathrm{~L}$ methanol for a week with 
sporadic stirring and shaking. As a result, greenish liquid was obtained. Then it was filtered via filter paper (Whatman No. 1). The filtrate was evaporated with rotary evaporator at specific temperature and pressure to get incompletely dried crude methanol extract (CME). It was further evaporated by freeze drier randomly for 24 hours. After complete evaporation, the remaining residues weighing $50 \mathrm{~g}$ were obtained. Later, the extract was utilized for the determination of antioxidant power and antimicrobial activity of $P$. multicaule.

\section{Results and discussion}

\section{Determination of DPPH Free Radical Scavenging Capacity Protocol}

The DPPH is crystalline organic compound having violet color which plays key part in the scavenging of free radical. This searching test was determined with the help of fundamental techniques managed by Barku, Naseena and Yan [26, 27]. The DPPH method was mainly exercised for the assessment of antioxidants in the plant extract. The CME solutions were prepared with numerous concentrations like $0.2 \mathrm{~mL}$ to $1 \mathrm{~mL}$ in $\mathrm{MeOH}$. Freshly made DPPH solution with quantity of $1 \mathrm{~mL}(0.1 \mathrm{mM}=3.943 \mathrm{mg} / 100 \mathrm{~mL}$ in $\mathrm{MeOH})$ were combined with $2 \mathrm{~mL}$ of all samples i.e., 0.2 to $1.0 \mathrm{~mL}$. In DPPH method, the ascorbic acid solution with same concentration was prepared and same solvent was used for positive control. After that the test samples and the DPPH solution were mixed and kept in the dark for half hour. UV-VIS absorbance was measured at a wavelength of $517 \mathrm{~nm}$, for the calculation of control absorbance $\mathrm{MeOH}$ was utilized as a substitute of the plant extract. $\mathrm{MeOH}$ was used only for the assessment of blank absorbance. The following equation is used to determine the plant extract ability for quenching the absorbance of DPPH free radicals.

$\%$ age $I=\frac{(\mathrm{Ac}-\mathrm{As})}{A c} \times 100$

Where,

\% age I: Is percentage absorbance/inhibition.

Ac: symbolizes control absorbance.

As: for standard or CME absorbance.

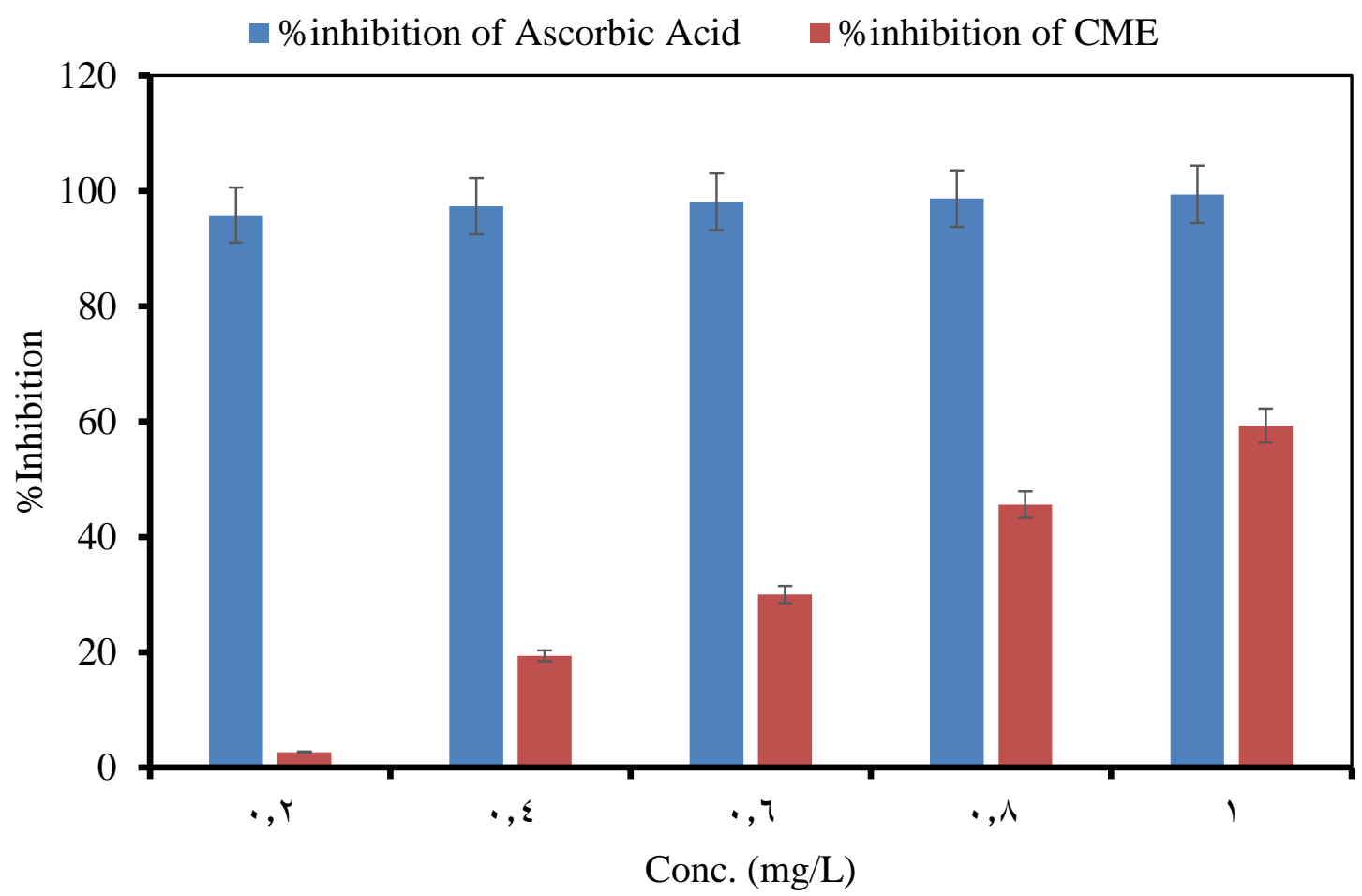

Fig.(2): \% inhibition of DPPH by AA and CME. 


\section{TAC or PM Assessment}

TAC stands for total antioxidant capacity and the PM stands for phosphomolybdenum. The total antioxidant capacity of CME of $P$. multicaule can be determined by the following method. The basic concept is to produce a green phosphomolybdenum Mo (V) complex, at acidic condition by the plant extract. Mo 'VI' can be reduced to Mo ' $\mathrm{V}$ ' complex. Spectroscopic method can be utilized to assess the total antioxidant capacity [28]. For this, 1 $\mathrm{mL}$ CME with various concentrations such as $(0.2$ to $1.0 \mathrm{mg} / \mathrm{ml})$ was combined with
Molybdate solution [0.6 M, $\mathrm{H}_{2} \mathrm{SO}_{4}, 28 \mathrm{mM}$, $\mathrm{Na}_{3} \mathrm{PO}_{4}$ and $\left.4 \mathrm{mM} \quad\left(\mathrm{NH}_{4}\right)_{6} \mathrm{Mo}_{7} \mathrm{O}_{24}\right]$. Subsequently, the reaction mixtures were put in test tubes, then put it at $95^{\circ} \mathrm{C}$ for incubation of 90 minutes. The absorbance was assessed via spectrophotometers which were fixed at $695 \mathrm{~nm}$ verses blank. To prepare blank, $5 \mathrm{~mL}$ of reagent solution was mixed with $0.5 \mathrm{~mL}$ of $\mathrm{MeOH}$ and then incubated under the similar condition. TAC is shown as mg equivalent of ascorbic acid (AA) which is expressed in the Fig.(3).

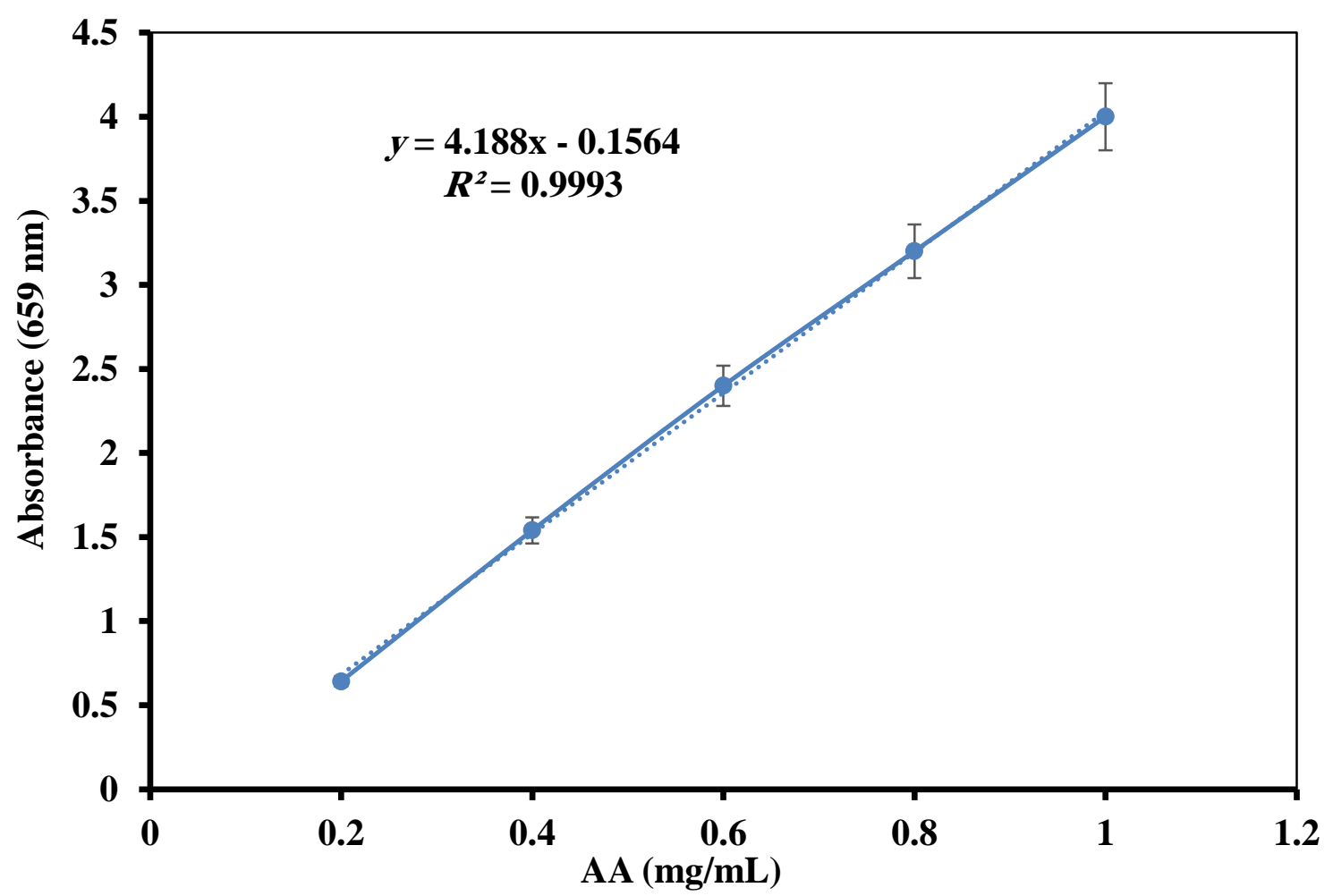

Fig.(3): Typical standardization curve for AA against ammonium molybdate for the assessment of total antioxidant capacity.

\section{Ferric Reducing Antioxidant Power Protocol (FRAP)}

An advanced and developed technique which is known as FRAP method was used to determine the ferric ion reduction power of (CME) of P. multicaule [29]. The aim of the technique is to reduce ferric ion $\left(\mathrm{Fe}^{+3}\right)$ into ferrous ions $\left(\mathrm{Fe}^{+2}\right)$ in the tripyridyltriazine complex, a central metal complex, at low level of PH. Preparation of FRAP solution was done by the combination of $1 \mathrm{~mL}$ of $10 \mathrm{mM}$ tripyridyltriazine "TPTZ" in $40 \mathrm{mM}$ hydrochloric acid to acetate buffer with $10 \mathrm{~mL}$ of $23 \mathrm{mM}$ then added $1 \mathrm{~mL} \mathrm{FeCl}$ in the ratio of 10:1:1 vol/vol. PH for FRAP reagent was
3.6. The whole solution was prepared and consumed freshly. Almost, $2 \mathrm{~mL}$ of FRAP reagent and $1 \mathrm{~mL}$ of distilled water was added to plant extract for example 0.2 to $1 \mathrm{~mL}$ in the test tube. Then heated the entire solution for 30 minutes at $38^{\circ} \mathrm{C}$. Absorbance was calculated at $593 \mathrm{~nm}$ through UV/VIS spectrophotometer. The same method was applied for the standard ascorbic acid (AA). Blank was made in which only acetate buffer was utilized and calculated the readings. The results were shown as $\mathrm{mg}$ of ascorbic acid/gram of plant extract. 


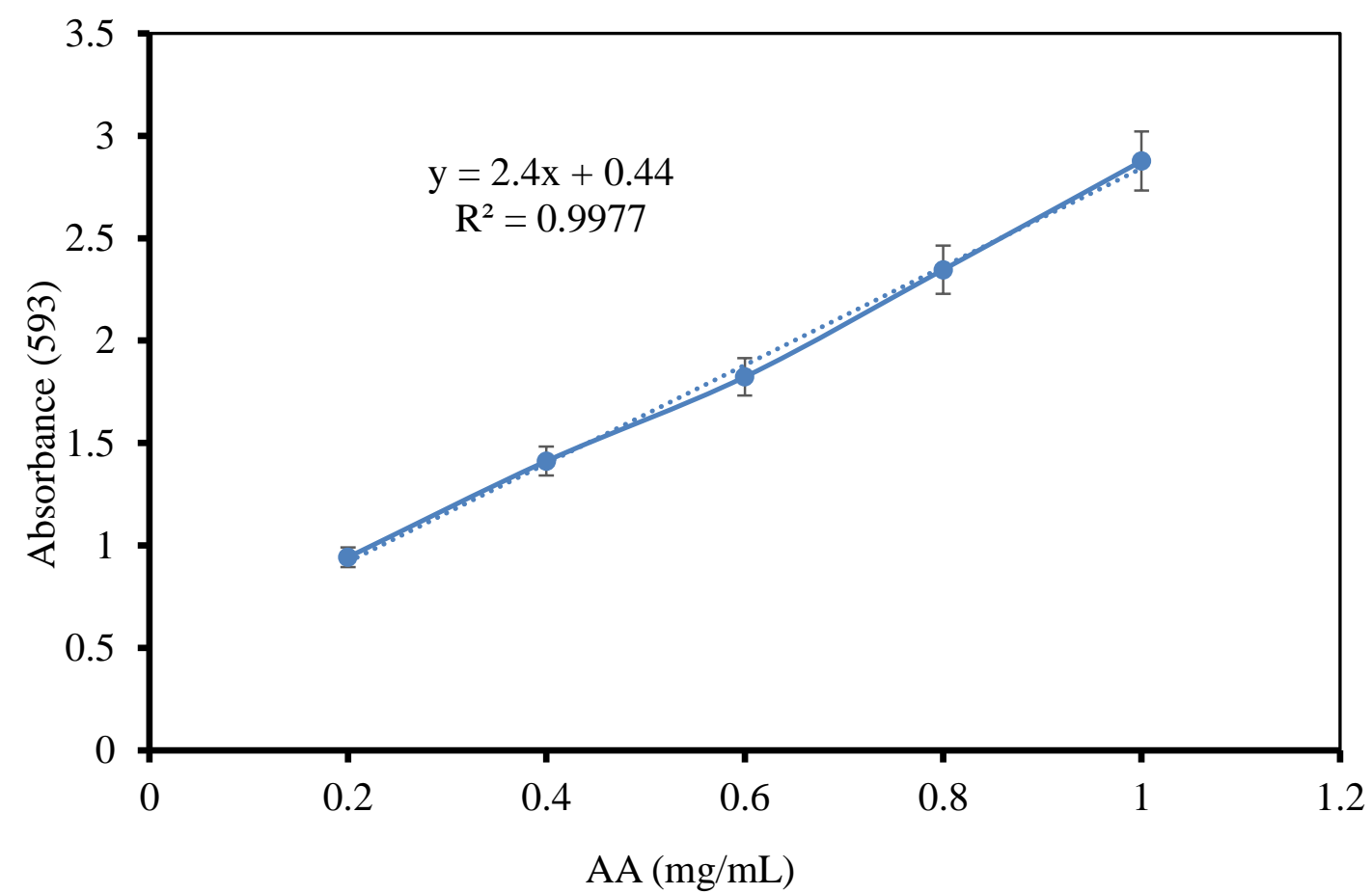

Fig.(4): Calibration for AA using FRAP method.

Determination of Ferric Ion Antioxidant Reducing Power Protocol (RP)

The reducing antioxidant power protocol of CME of $P$. multicaule was measured by a technique offered by Saeed et al with less changes [30]. Fresh solutions were prepared by the combination of $10 \mathrm{mg}$ of plant extract with $100 \mathrm{~mL}$ of $\mathrm{MeOH}$. Furthermore, different quantities of the plant extract like 0.2 to $1 \mathrm{~mL}$ were made and mixed with $1 \% \quad 2.5 \mathrm{~mL}$ potassium ferricyanide and $2.5 \mathrm{~mL}(0.2 \mathrm{M})$ buffer phosphate. The $\mathrm{pH}$ level keeps at a constant range 6.60. This mixture was kept warm at $50^{\circ} \mathrm{C}$ for 30 minutes in water bath. After incubation, $10 \%$ of trichloro acetic acid with $2.5 \mathrm{~mL}$ was also mixed in the solution. Then the whole solution was added in the tube for centrifugation at $1500 \mathrm{rpm}$ for 15 minutes. After that, the superior layer of the solution was separated with the help of micropipette and then mixed the same amount of deionized water, also mix freshly prepared $0.1 \mathrm{M} \mathrm{FeCl} 3$ solution. The absorbance was assessed at $700 \mathrm{~nm}$ via ultraviolet visible spectrophotometer. Control was made in the same way eliminating the sample. Various concentrations of ascorbic acid were utilized as standard. The high value absorbance of sample shows the increase in the reduction potential of $P$. multicaule. The raised value of absorbance is shown in Fig.(5). 


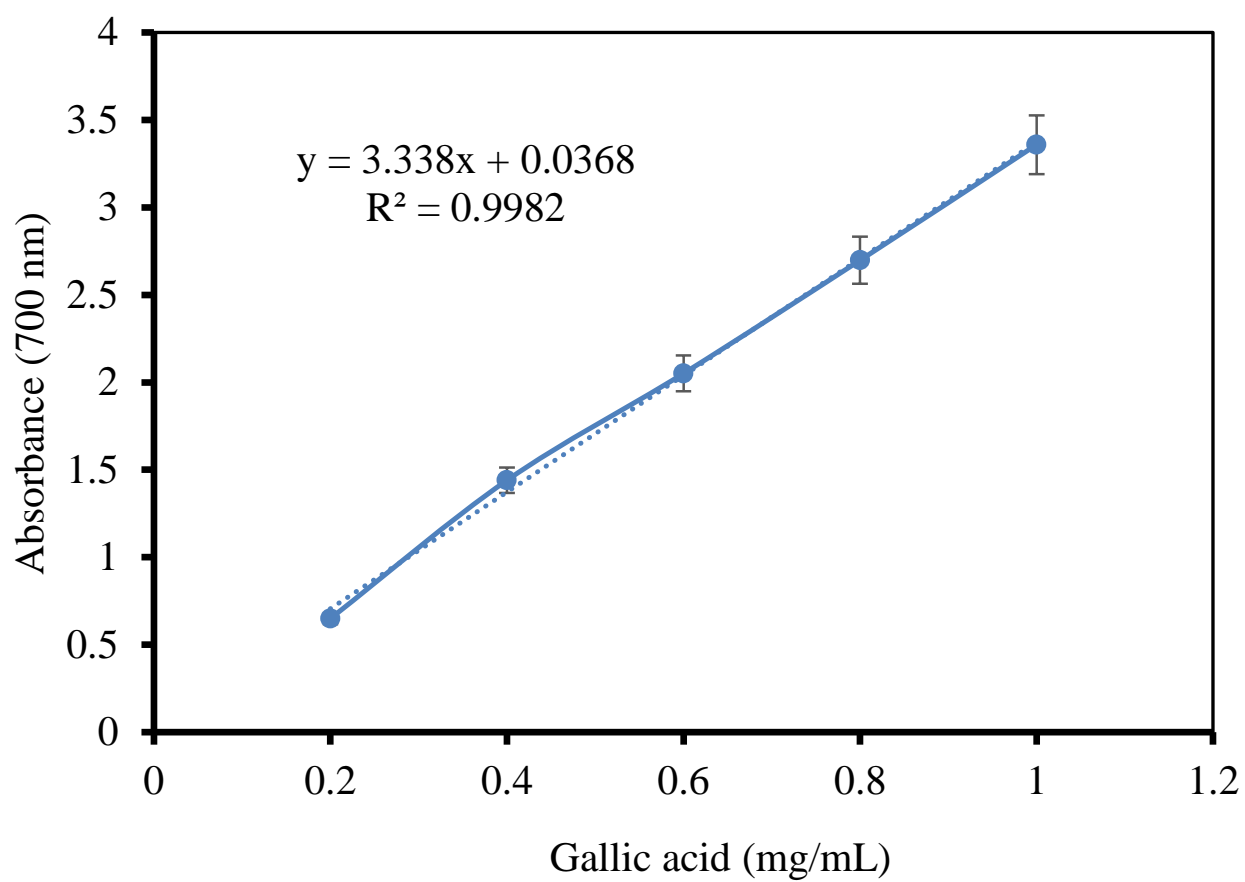

Fig.(5): Standardization curve for Gallic acid $\mathrm{mg} / \mathrm{mL}$.

\section{Evaluation of Antimicrobial Activity} (Antibacterial)

\section{Agar Well Diffusion Method}

This method is also known as Muller Hinton agar. It is used all over the world to determine the antibacterial activities of medicinal plants $[31,32]$. The procedure is similar to disk diffusion method. The CME of $P$. multicaule was examined against two pathogenic bacteria. The agar plate surface is injected by the microbes entirely. A bore is created with tip or cork borer with the diameter of 6 to $7 \mathrm{~mm}$. Then the desired concentration of $\mathrm{CME}$ was poured into it. After that the agar plates were incubated properly for the specific period of time depending on the microorganism. The antibacterial agents present in the test solution spread in the medium that stopped the growth of the microbes which were under the experiment. The result of this experiment was tabulated.

Table (1)

Shows the antibacterial activities of $P$. multicaule and $E$. stellate.

\begin{tabular}{|l||c|c|}
\hline Name of Plants & E. coli & S. aureus \\
\hline \hline A1 P. multicaule & $14 \mathrm{~mm}$ & $16 \mathrm{~mm}$ \\
\hline \hline A2 E. stellate & $13 \mathrm{~mm}$ & $14 \mathrm{~mm}$ \\
\hline
\end{tabular}

\section{Results and Discussion}

To determine the antioxidants power in the CME of $P$. multicaule which belongs to Umbelliferae family. It contains approximately three thousand species and almost 56 genera in which 167 species have been recorded in Pakistan. Moreover, the antioxidant activity of this plant is investigated by four well known methods. Traditionally, P. multicaule has been used for wound healing and preserving the meat [33]. The comprehensive utilization of ultraviolet visible spectrophotometers in research laboratory played significant role in the evaluation of antioxidant in the CME of $P$. multicaule [34]. These methods are inexpensive and very relaxed to use which boosts their practicality [35]. It is known that all free radicals have high reactivity and instability due to unpaired electrons. They can get stability through conjugation and resonance phenomena.

DPPH protocol was nominated to determine the extent of antioxidants in the extract of $P$. multicaule. The DPPH radical can be utilized in solvent such as methyl alcohol and water [36]. The absorbance of photons which have wavelength of $517 \mathrm{~nm}$ for the electronic transition of such free radical. When DPPH gain hydrogen atom the absorbance value decreases with consequent color change from purple to yellow. It is very sensitive to 
identify compounds at very small concentration. It can examine several samples in short period of time. The reducing power calculate the less activity of oxidants as defined in reduction oxidation reactions. The reduction power of a compound is significant indicator for antioxidant activity. The reduction power of chemical compound is directly proportional to the high extract absorbance. The change in absorbance band and color can be evaluated as the free radical accepts a proton from the antioxidants which are available in the CME. Furthermore, the strength of CME is calculated in comparison with ascorbic acid. The $\%$ age inhibition value of DPPH increases to $99.39 \%$ of $P$. multicaule.

Furthermore, TAC or PM investigation describes the reduction of Molybdenum (VI) to Molybdenum (V). Fundamentally, this method is used to determine the rate of reduction reaction among molybdenum ligands and antioxidants. Moreover, it directly measures the reduction of antioxidants with the value of $10.85 \mathrm{mg}$ of ascorbic acid/g of $P$. multicaule extract. This assay is different from FRAP protocol, since it does not depend on the amount of free metal ions. It also provides green phospho molybdenum compound. Therefore, it shows idiosyncrasy amid in vitro antioxidant analysis.

In addition, the large amount of antioxidants present in the plant was identified by the use of FRAP protocol. Here, protons are available in the crude methanolic extract of $P$. multicaule which convert Ferric ion complex ( $\mathrm{Fe}^{+3}$ tripyridyltriazine) having no colour to a bluish colour Ferrous complex $\left(\mathrm{Fe}^{+2}\right.$ tripyradiltriazine). The absorbance was observed at $593 \mathrm{~nm}$. Standard calibration curve of ascorbic acid is used to calculate the antioxidants present in $P$. multicaule. The equation called regression equation, $y=2.4 \mathrm{x}+$ 0.44 , it is obtained through the typical curve of ascorbic acid in graph. In above equation, $\mathrm{x}$ indicates amount of vitamin $\mathrm{C}$ and $\mathrm{y}$ denotes absorbance. The FRAP method shows amount of $40 \mathrm{mg}$ of vitamin $\mathrm{C} / \mathrm{g}$ of the plant extract. These quantities of antioxidants show that $P$. multicaule contains more antioxidants.

Consequently, the reduction of $P$. multicaule is also counted with the help of reduction of ferric ion $\left(\mathrm{Fe}^{+3}\right)$ to ferrous ion
$\left(\mathrm{Fe}^{+2}\right)$, because the presence of antioxidants in the CME is associated with ascorbic acid standard. As a result, the RP shows $3.29 \mathrm{mg} / \mathrm{g}$ of ascorbic acid concentration. In this, potassium ferricyanide reduces to ferrocyanide in the presence of ferric chloride. Which is shown in the following equation.

\section{$\mathrm{K}_{4}\left[\mathrm{Fe}(\mathrm{CN})_{6}\right]+\mathrm{FeCl}_{3} \rightarrow \mathrm{K}_{4}\left[\mathrm{Fe}(\mathrm{CN})_{6}\right]$}

Potassium ferrocyanide further changes into ferri ferrocyanide because of crude methanolic extract of plant. The high absorbance indicated that $P$. multicaule is rich in antioxidant.

Every individual protocol calculated the antioxidant activity under definite criteria useful for that system. Therefore, it is not accurate to over simplify data obtained as indicator of total antioxidant capacity. Antioxidant activity of the plant extract is dependent on the extraction techniques and conditions like temperature and solvent. In most experimentations, the solvent utilized were methyl alcohol, ethyl alcohol, ethyl acetate, boiling water and acetone.

The second part of the experimental work is the assessment of antiseptic activities. The agar well diffusion method was utilized to examine the plant extract verses pathogens. The agar plates were supplied with microbes and then CME of desired concentration were tested against the bacteria. The growth inhibition zones indicated that the plant have high tendency of antibacterial activity. The result of experiment was shown in the table.

\section{Conclusion}

This investigation clarifies that there was greater amount of antioxidants existing in the CME of $P$. multicaule by the application of four well recognized methods. Such as DPPH assay, TAC, FRAP assay and RP assays. The capacity of DPPH assay of $P$. multicaule was $190 \mathrm{mg} / \mathrm{g}$ of ascorbic acid concentration. Additionally, for the TAC and FRAP, the values of extracts were $10.85 \mathrm{mg}$ and $40 \mathrm{mg}$ of ascorbic acid/g of $P$. multicaule extract respectively. In addition, the RP shows 3.29 $\mathrm{mg} / \mathrm{g}$ of ascorbic acid concentration. Nowadays bacterial contaminations have become significant scientific menace, which are associated with illnesses and death because 
of the improvement of bacterial opposition to the present antibacterial agents. As a result, procedures for antibacterial vulnerability analysis and realizing unique antimicrobial agents have been exercised and carry on to be advanced. However, when checking the natural product. Few changes of standardized assay are mostly demanded. Hence, we have not to change the basics of microbiology by diluting the media and using more concentrated inoculum. If we consider the use of solvent that can affect the growth of microorganism tested. A standardizes assay can be the solution of correct experimental approach and allow other scientist to relate the consequence. The plant $p$-multicaule proved to have high concentration of antibacterial agents. Which were examined against two bacteria namely Escherichia coli and Staphylococcus aureus which exhibited 14 $\mathrm{mm}$ and $16 \mathrm{~mm}$ zones of inhibition respectively by the use of agar well diffusion method.

\section{Acknowledgement}

We are really thankful to the Chemistry Department, University of Balochistan Quetta for cooperating this task.

Authors assistances regarded and planned the research: Najeebullah Kakar, Samiullah Achakzai and RB Tareen accomplished the experimentations: Najeebullah Kakar evaluated the data: Najeebullah Kakar, Samiullah Achakzai, Muhammad Asghar and Naqeebullah Khan donated resources/ study/ apparatuses.

\section{References}

[1] Sherman P W., Hash G A., "Why vegetable recipes are not very spicy", Evolution and Human Behavior, 22(3), 147163, 2001.

[2] Stepp J R., Moerman D E., "The importance of weeds in ethnopharmacology", Journal of ethnopharmacology, 75(1), 19-23, 2001.

[3] Rahman M S., Rahman M Z., Wahab M A., Chowdhury R., Rashid M A. "Antimicrobial activity of some indigenous plants of Bangladesh". Dhaka University Journal of Pharmaceutical Sciences, 7(1), 23-26, 2008.
[4] Abbed A M., "Investigation Effects of Lavenders Flowers Extracts on Catalase Activity and Some Microorganisms", AlNahrain Journal of Science, 22(1), 55-61, 2019.

[5] Nasir E., Ali S I., "Flora of West Pakistan. Islamabad, Pakistan", Agric Research Council 1-190, 1971.

[6] Hamayun M., "Ethnobotanical profile of Utror and Gabral valleys, district Swat, Pakistan”, Ethnobotanical leaflets, 2005(1), 9, 2005.

[7] Erdemgil F Z., Ilhan S., Korkmaz F., Kaplan C., Mercangöz A., Arfan M., Ahmad S., "Chemical Composition and Biological Activity of the Essential Oil of Perovskia atriplicifolia. From Pakistan", Pharmaceutical biology, 45(4), 324-331, 2007.

[8] Zhu Y Z., Huang S H., Tan B K H., Sun J., Whiteman M., Zhu Y C., "Antioxidants in Chinese herbal medicines: a biochemical perspective", Natural product reports, 21(4), 478-489, 2004.

[9] Majhenic L., Skerget M., \& Knez Z. "Antioxidant and antimicrobial activity of guarana seed extracts", Food chemistry, 104(3), 1258-1268, 2007.

[10] Hussain A I., Anwar F., Iqbal T., Bhatti I A., "Antioxidant attributes of four Lamiaceae essential oils", Pak. J. Bot, 43(2), 1315-1321, 2011.

[11] Glantzounis G K., Tsimoyiannis E C., Kappas A M., Galaris D A., "Uric acid and oxidative stress", Current pharmaceutical design, 11(32), 4145-4151, 2005.

[12] El-Sohemy A., Baylin A., Kabagambe E., Ascherio A., Spiegelman D., Campos H., "Individual carotenoid concentrations in adipose tissue and plasma as biomarkers of dietary Intake", The American journal of clinical nutrition, 76(1), 172-179, 2002.

[13] Sowell A L., Huff D L., Yeager P R., Caudill S P., Gunter E W., "Retinol, alphatocopherol, lutein/zeaxanthin, betacryptoxanthin, lycopene, alpha-carotene, trans-beta-carotene, and four retinyl esters in serum determined simultaneously by reversed-phase HPLC with multiwavelength detection", Clinical chemistry, 40(3), 411-416, 1994 
[14] Stahl W., Schwarz W., Sundquist A R., Sies H., "Cis-trans isomers of lycopene and $\beta$-carotene in human serum and tissues", Archives of biochemistry and biophysics, 294(1), 173-177, 1992.

[15] Zita C., Overvad K., Mortensen S A., Sindberg C D., Moesgaard S., Hunter D A., "Serum coenzyme Q10 concentrations in healthy men supplemented with $30 \mathrm{mg}$ or $100 \mathrm{mg}$ coenzyme Q10 for two months in a randomised controlled study", Biofactors, 18(1- 4), 185-193, 2003.

[16] Duda-Chodak A., Tarko T., Rus M., "Antioxidant activity and total polyphenol content of selected herbal medicinal products used in Poland", Herba Polonica, 57(1), 2011.

[17] Duda-Chodak A L E K S A N D R A., Tarko T O M A S Z., Rus M A G D A L E $\mathrm{N}$ A., "Antioxidant activity of selected herbal plants", Herba polonica, 55(4), 6577, 2009.

[18] Al-Majedy Y K., Ibraheem H H., Jassim L S., \& Al-Amiery A A., "Antioxidant Activity of Coumarine Compounds", AlNahrain Journal of Science, 22(1), 1-8. 2019.

[19] Goldstraw P., "The 7th Edition of TNM in Lung Cancer: what now", Journal of Thoracic Oncology, 4(6), 671-673, 2009.

[20] Lipinski C A., Lombardo F., Dominy B W., Feeney $\mathrm{P}$ J., "Experimental and computational approaches to estimate solubility and permeability in drug discovery and development settings", Advanced drug delivery reviews, 23(1-3), 3-25, 1997.

[21] Hunter D., "Life in the fast lane: Highthroughput chemistry for lead generation and optimization", Journal of Cellular Biochemistry, 84(S37), 22-27, 2001.

[22] Maghrani M., Zeggwagh N A., Michel J B., Eddouks M., "Antihypertensive effect of Lepidium sativum L. in spontaneously hypertensive rats", Journal of ethnopharmacology, 100(1-2), 193-197, 2005.

[23] Mahmoud A., Mahmood A., Tabassum A., "Ethnomedicinal survey of plants from District Sialkot, Pakistan", J Appl Pharm, 3, 212-220, 2011.
[24] Essawi T., Srour M., "Screening of some Palestinian medicinal plants for antibacterial activity", Journal of ethnopharmacology 70(3), 343-349, 2000.

[25] Akram E., Daham S N., Rashad A A., \& Mahmood A E., "Synthesis and Evaluation the Activity of 1, 3, 4-Thiadiazole Derivatives as Antibacterial Agent Against Common Pathogenic Bacteria", Al-Nahrain Journal of Science, 22(1), 25-32. 2019.

[26] Baqi A., Tareen R B., Mengal A., Khan N., Behlil, F., Achakzai A K K., \& Faheem M., "Determination of antioxidants in two medicinally important plants, Haloxylon griffithii and Convolvulus leiocalycinus of Balochistan", Pure and Applied Biology, 7(1), 296-308. 2018.

[27] Brand-Williams W., Cuvelier M E., Berset C L W T., "Use of a free radical method to evaluate antioxidant activity", LWT-Food science and Technology, 28(1), 25-30, 1995.

[28] Saeed N., Khan M R., Shabbir M., "Antioxidant activity, total phenolic and total flavonoid contents of whole plant extracts Torilis leptophylla L", BMC complementary and alternative medicine, 12(1), 221, 2012.

[29] Shetty S., Udupa S., Udupa L., "Evaluation of antioxidant and wound healing effects of alcoholic and aqueous extract of Ocimum sanctum Linn in rats", Evidence-Based Complementary and Alternative Medicine, 5(1), 95-101, 2008.

[30] Prieto P., Pineda M., \& Aguilar M., "Spectrophotometric quantitation of antioxidant capacity through the formation of a phosphomolybdenum complex: specific application to the determination of vitamin E", Analytical biochemistry, 269(2), 337-341, 1999.

[31] Magaldi S., Mata-Essayag S., De Capriles C H., Perez C., Colella M T., Olaizola C., Ontiveros Y., "Well diffusion for antifungal susceptibility testing", International journal of infectious diseases, 8(1), 39-45, 2004.

[32] Valgas C., Souza S M D., Smania E F., \& Smania Jr A., "Screening methods to determine antibacterial activity of natural products", Brazilian Journal of Microbiology, 38(2), 369-380, 2007. 
[33] Pandith J I., "Phytochemical screening of certain plant species of Agra city", Journal of drug delivery and therapeutics. 2(4), 2012.

[34] Khan A M., Qureshi R A., Ullah F., Gilani S A., Nosheen A., Sahreen S., Murad W., "Phytochemical analysis of selected medicinal plants of Margalla Hills and surroundings",Journal of medicinal plants research, 5(25), 6055-6060, 2011.

[35] Pelozo M I D G., Cardoso M L C., Mello J C P D., "Spectrophotometric determination of tannins and caffeine in preparations from Paullinia cupana var. sorbilis", Brazilian Archives of Biology and Technology, 51(3), 447-451, 2008.

[36] Bueno F G., Machareth M A., Panizzon G P., Lopes G C., Mello J C., Leite-Mello E V "Development of a UV/Vis spectrophotometric method for analysis of total polyphenols from Caesalpinia peltophoroides Benth", Química Nova, 35(4), 822-826, 2012. 